\title{
Daily Stock Price Regime Model Detection using Markov Switching Model
}

\author{
${ }^{1}$ Wiwik Prihartanti*, ${ }^{2}$ Dwilaksana Abdullah Rasyid and ${ }^{\mathbf{3}}$ Nur Iriawan \\ ${ }^{1}$ Department of Business Administration, Faculty of Social and Political Science \\ Universitas WR Supratman \\ 60111 Surabaya, Indonesia \\ ${ }^{2}$ Master Student of Department of Statistics, Faculty of Social and Data Analysis \\ Institut Teknologi Sepuluh Nopember \\ 60111 Surabaya, Indonesia \\ ${ }^{3}$ Department of Statistics, Faculty of Social and Data Analysis \\ Institut Teknologi Sepuluh Nopember \\ 60111 Surabaya, Indonesia \\ *Corresponding author: wiwik.pri@gmail.com
}

Article history

Received: 9 April 2019

Received in revised form: 11 July 2020

Accepted: 16 July 2020

Published online: 1 August 2020

\begin{abstract}
Changes in stock prices randomly occur due to market forces with reoccurrence possibilities. This process, also known as the structural break model, is captured through changes in the linear model parameters among periods with the Markov Switching Model (MSwM) used for detection. Furthermore, using the smallest Akaike Information Criterion (AIC) value on all feasible MSwM alternatives formed for a daily stock price, the complete MSwM model with its Markov transition is determined. This method has been tested and applied to daily stock price data in several sectors. The result showed that the number of regime models coupled with its transition probability helped investors make investment decisions.
\end{abstract}

Keywords Stock price; EM Algorithm; Regime model; Markov Switching Model; AIC; Transition probability

Mathematics Subject Classification 60J20, 37M10, 93C30, 62F07, 47J25

\section{Introduction}

The Stock Exchange, as one of the capital market institutions, plays a significant role in the economic development of a country. It is an institution through which stock, bonds, and other financial instruments of companies and governments are traded. Furthermore, it also organizes and provides a systematic mechanism to bring together selling and buying securities within or outside the exchange from other parties with the aim of trading. A stock is a form of financial instrument that shows the ownership of a person or an entity against a company. Shares are 
used by companies to acquire additional capital by selling them to investors through the Stock Exchange. Similarly, investors buy shares to get a return based on investments on a company's assets.

However, investors need to be smart in determining the safest stock choices with high potential from a variety of increasing types of shares listed on the stock exchange. Their share types are generally in the Blue Chip category because they choose from companies with the largest capitalization. Blue Chip or first-level shares, which are located in the LQ45 company index, are heavily traded shares with high liquidity because they are from large organizations with stable income. Serial data on stock prices suddenly change at any time due to market turmoil. These changes tend to occur in the mean, variance, and in a combination of both attributes. The Indonesia Composite Stock Price Index (IHSG) decreased for the first time by 1.83 percent at the close of trading after the Idul Fitri holiday on Wednesday, June 20, 2018, at 5,884.04 levels. This led to cheap stock prices scattered on the stock market, which created an opportunity for smart investors to invest [1].

Satchell [2] stated that it is difficult to determine the market indexes, serial styles, and statistical factors of a stock market, therefore, the structural change model is unavoidable. Huarng's [3] research on switching regimes in accordance with the frequency of occurrences stated that it is important to improve forecasting accuracy. The conventional switching regime studies generally use econometric methods $[4,5]$. Meanwhile, the Markov-switching vector error model was used by Syllignakis and Kouretas [6] to examine the dynamic relationship between euro exchange rates against 10 emerging markets in Central and Eastern Europe. Fuentes and Rios [7] used the regime's switching methods to study the role of Central Reserve Banks in the dollarized economy. Huarng et al. [8] initiated studies on regime-switching with clustering methods used to analyze structural changes in the Taiwan Stock Exchange Capitalization Weighted Stock Index (TAIEX). Huarng et al. [9] also used the grouping method to model the structural changes in the number of Taiwan tourism. The latest research conducted by Huarng [10] involved the qualitative methods, fuzzy sets, and qualitative comparative analysis (fsQCA).

Markov Chain modeling method uses the autoregressive method to determine the patterns of the stock price data that indicate any sudden changes [11]. This study analyzes the Blue Chip category shares from the transportation, households, and telecommunication sectors, which are represented by PT. Astra International, PT. Unilever and PT. Telekomunikasi Indonesia.

Due to fluctuations in the prices of individual stocks on the above-listed sectors, it is necessary to determine regime change's ability to improve analysis performance. Therefore, this research uses MSwM to model stock price movements with a structural change phenomenon.

\section{Methodology}

\subsection{Markov Switching Model}

The mean ad variance values of the Markov switching model is written in equation $(1)[12,13]$.

$$
z_{t}=\mu_{s t}+\varepsilon_{s_{t}}
$$

where $\mu_{s_{t}}$ is the mean model of states or regimes $s_{t}$ and $\varepsilon_{s_{t}} \sim N\left(0, \sigma_{s_{t}}^{2}\right)$ is unobserved or residual. The unobserved random variables are denoted by $s_{t}$, where $s_{t} \in\{1,2, \ldots, M\}$ and $M$ 
is the number of states. When MSwM has an $M$ number of states, equation (1) is written as follows:

$$
\left\{\begin{array}{c}
z_{t}=\mu_{1}+\varepsilon_{1} \text { if } s_{t}=1, \\
z_{t}=\mu_{2}+\varepsilon_{2} \text { if } s_{t}=2, \\
\vdots \\
z_{t}=\mu_{M}+\varepsilon_{M} \text { if } s_{t}=M .
\end{array}\right.
$$

When state $i$ move to $j$, the probability of the Markov chain is written as follows:

$$
p\left\{s_{t}=j \mid s_{t-1}=i, s_{t-2}=k, \ldots\right\}=p\left\{s_{t}=j \mid s_{t-1}=i\right\}=p_{i j},
$$

where $p_{i j} \geq 0$ for $i, j=1,2, \cdots, M$, and $\sum_{j=1}^{M} p_{i j}=1$. The probability of the changing regimes is, therefore, represented as follows:

$$
\mathbf{P}=\left[\begin{array}{llll}
p_{11} & p_{12} & \cdots & p_{1 M} \\
p_{21} & p_{22} & \cdots & p_{2 M} \\
\vdots & \vdots & \ddots & \vdots \\
p_{M 1} & p_{M 2} & \cdots & p_{M M}
\end{array}\right]
$$

where $p_{i M}=1-p_{i 1}-p_{i 2}-\ldots-p_{i(M-1)}$ for $i=1,2, \ldots, M$.

The simplest writing model for the combination of Markov Switching on $M$ state with the Autoregressive on order $r$ is in the form of $\operatorname{MSw}(M)$ - $\mathrm{AR}(r)$. For $r=1$, the $\operatorname{MSw}(M)-\mathrm{AR}(1)$ is written as follows:

$$
\left\{\begin{array}{c}
z_{t}=\left(\phi_{01}+\phi_{11} z_{t-1}\right)+\varepsilon_{1}, \text { if } s_{t}=1, \\
z_{t}=\left(\phi_{02}+\phi_{12} z_{t-1}\right)+\varepsilon_{2}, \text { if } s_{t}=2, \\
\vdots \\
z_{t}=\left(\phi_{0 M}+\phi_{1 M} z_{t-1}\right)+\varepsilon_{M}, \text { if } s_{t}=M .
\end{array}\right.
$$

The main duty of the Markov switching model functions is to determine the number of optimal regimes used to represent the data series. However, determining the number of states is tasking due to the difficulty in distributing the usual likelihood ratio test with asymptotical $\chi^{2}$ regularity conditions. Persio and Frigo [14] used the maximum likelihood to estimate the Markov switching model in serial financial time modeling by incorporating external factors from the data series. The Markov's state was identified during a sudden change in the behavior of financial quantities by indicating the existence of socio-political factors that substantially changed the observed economic scenario.

\subsection{Expectation Maximization (EM)}

The EM algorithm is an iterative method used to estimate the function's parameters when the Maximum Likelihood Estimation approach goes to a non-close form [15]. EM iteration method is repeatedly carried out in the expectation and maximization stages until it reaches convergence. Equation (1) integrates with the number of switching model in $M$ regimes to form a mixture of normal components [16] with the following likelihood function

$$
L(\varepsilon)=\prod_{i=1}^{n} \sum_{s_{t}=1}^{M}\left(\pi_{s_{t}}\left(\frac{1}{\sigma_{s_{t}}^{2} \sqrt{2 \pi}}\right) \exp \left(-\frac{1}{2}\left(\frac{\varepsilon_{i s_{t}}}{\sigma_{s_{t}}}\right)^{2}\right)\right)
$$


where $\pi_{s_{t}}$ is the proportion of regime $s_{t}$ in the model, $\pi_{s_{t}} \geq 0, \sum_{s_{t}=1}^{M} \pi_{s_{t}}=1$, and $n$ is the number of data.

The EM algorithms are used to estimate parameters, while the Markov Switching Models utilizes a dummy vector, with $\tau_{i}=\left(\tau_{i 1}, \tau_{i 2}, \ldots, \tau_{i M}\right)$, and $i=1,2, \ldots, n$ to determine the set of unobservable latent variables. For $s_{t}=1,2, \ldots, M$, the latent variable $\tau_{i s_{t}}$ is set to one, $\tau_{i s_{t}}=1$, when the $i$-th data is the member of the $s_{t}$-th regime, that produces the best prediction, and $\tau_{i s_{t}}=0$ for the other $s_{t}$. The expectation stage, for the certain $i$-th data, is repeatedly estimated using equation(7).

$$
\tau_{i s_{t}}=\frac{\frac{\pi_{s_{t}}}{\sigma_{s_{t}}} \exp \left(-\frac{1}{2}\left(\frac{\varepsilon_{i s_{t}}}{\sigma_{s_{t}}}\right)^{2}\right)}{\sum_{s_{t}=1}^{M}\left(\frac{\pi_{s_{t}}}{\sigma_{s_{t}}} \exp \left(-\frac{1}{2}\left(\frac{\varepsilon_{i s_{t}}}{\sigma_{s_{t}}}\right)^{2}\right)\right)}
$$

For certain $i$-th data, the largest $\tau_{i s_{t}}, s_{t}=1,2, \ldots, M$, is used to set this data as membership of state $s_{t}$. Finally, the sum of $\tau_{i s_{t}}$, where $i=1,2, \ldots, n$, is employed to calculate $\tau_{s_{t}}=\sum_{i=1}^{n} \tau_{i s_{t}}$ which is then used to estimate the proportion of mixed components as adjusted $\pi_{s t}=\frac{\tau_{s_{t}}}{n}$. In the second step, the maximization stage is carried out, by estimating $\hat{\sigma}_{s t}^{2}$ using the estimated $\tau_{i s_{t}}$ and $\tau_{s_{t}}$ as in equation (8).

$$
\hat{\sigma}_{s_{t}}^{2}=\frac{\sum_{i=1}^{n} \tau_{i s_{t}} \varepsilon_{i s_{t}}^{2}}{\tau_{s_{t}}}
$$

After estimating all parameters, a more representative model for the data is selected using the AIC criteria. The smaller the AIC of a model, the better it describes the data [17].

\section{Research Variable}

Secondary data were obtained from the Yahoo Finance website taken from the date of the company's initial public offering (IPO) to investors until August 14, 2018. The data contains the closing price of the three highest liquidity stocks selected in each of the three sectors as the Blue Chip category on the Indonesia stock exchange. Data not recorded on certain days are imputed by replacing the missing data with the company's stock price previously recorded. The descriptions of the variables used in this paper are shown in Table 1.

Table 1: Research Variable

\begin{tabular}{|c|l|}
\hline Variable & \multicolumn{1}{|c|}{ Description } \\
\hline$Z_{1(t)}$ & The closing price of PT. Astra International (ASII) shares \\
\hline$Z_{2(t)}$ & The closing price of PT. Unilever Indonesia (UNVR) shares \\
\hline$Z_{3(t)}$ & The closing price of PT. Telekomunikasi Indonesia (TLKM) shares \\
\hline
\end{tabular}

The data structure used in this research, which informs the different initial date for the IPO of the three Blue Chip category companies in Indonesia is shown in Table 2. 
Table 2: Research Data Structure

\begin{tabular}{|c|c|c|c|}
\hline Company & Date & Observation & Data \\
\hline \multirow{3}{*}{ PT. Astra International } & $17-10-2000$ & 1 & $Z_{1(1)}$ \\
& $\vdots$ & $\vdots$ & $\vdots$ \\
& $14-08-2018$ & $n_{1}$ & $Z_{1\left(n_{1}\right)}$ \\
\hline \multirow{3}{*}{ PT. Unilever Indonesia } & $03-09-2003$ & 1 & $Z_{2(1)}$ \\
& $\vdots$ & $\vdots$ & $\vdots$ \\
& $14-08-2018$ & $n_{2}$ & $Z_{2\left(n_{2}\right)}$ \\
PT. Telekomunikasi Indonesia & $28-09-2004$ & 1 & $Z_{3(1)}$ \\
& $14-08-2018$ & $n_{3}$ & $\vdots$ \\
& & & $Z_{3\left(n_{3}\right)}$ \\
\hline
\end{tabular}

Notes:

$n_{1}$ : the number of observation data for PT. Astra International $n_{2}$ : the number of observation data for PT. Unilever Indonesia $n_{3}$ : the number of observation data for PT. Telekomunikasi

\section{Results and Discussion}

\subsection{Data Exploration}

Figure 1 shows the modeling, time series plot, and closing price of the data explored by the three companies. It also shows the stock price of PT. Astra International and PT. Telekomunikasi is not stationary towards the mean and variance of the two companies. For PT. Unilever, the series tends to be stationary in variance and not mean. In the third time series plot, the shares price tends to have an upward trend despite a decline in stock prices. Characteristics of the three company shares price are descriptively shown in Table 3.

Table 3: Characteristics of the Three Company Shares Price (Rupiah)

\begin{tabular}{|c|c|r|r|r|r|}
\hline Company & N & \multicolumn{1}{c|}{ Mean } & St Dev & \multicolumn{1}{c|}{ Min } & \multicolumn{1}{c|}{ Max } \\
\hline PT. Astra International & 4,389 & $3,882.30$ & $3,091.60$ & 88.9 & 9,150 \\
\hline PT. Unilever Indonesia & 3,646 & $20,628.00$ & $15,842.00$ & 49.0 & 55,900 \\
\hline PT. Telekomunikasi Indonesia & 3,391 & $2,233.70$ & $1,010.50$ & 825.0 & 4,800 \\
\hline
\end{tabular}

Table 3 showes that PT owns the highest price on average. This means that the shares are more profitable and classified as unsafe due to its large standard deviation. Conversely, the share of PT. Unilever is safer and more confident in providing smaller benefits compared to the other two companies. This is because it has the smallest standard deviation and a graph with an upward trend as shown in Figure 1c. 


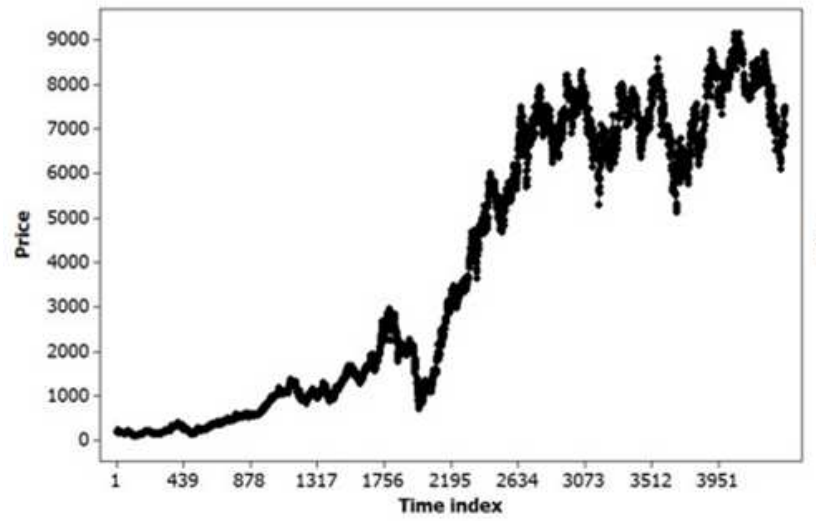

(a)

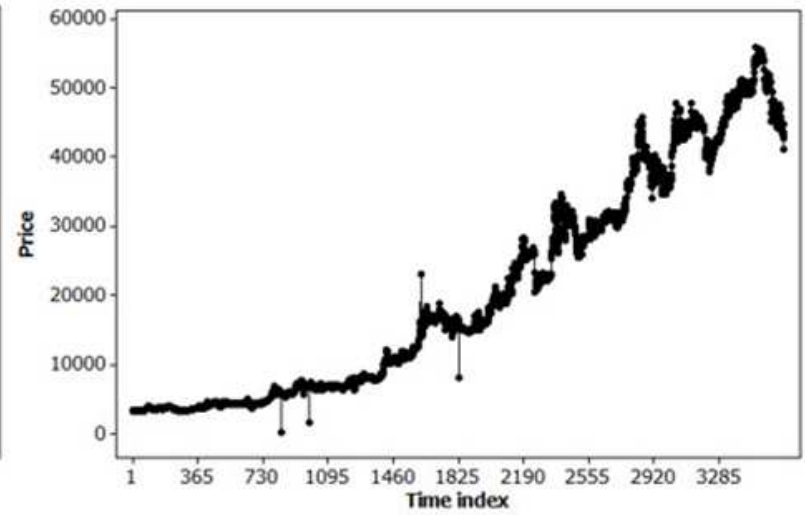

(b)

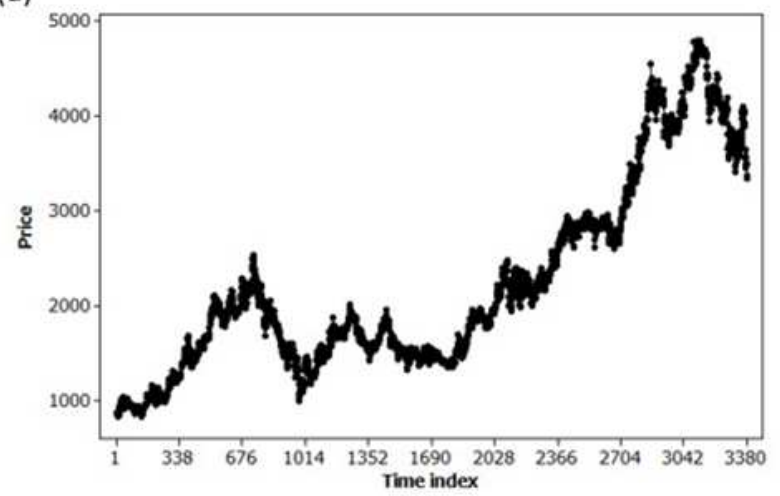

(c)

Figure 1: Time Series Plot of Shares (a) PT. Astra International (b) PT. Unilever Indonesia (c) PT. Telekomunikasi Indonesia.

Figure 2 shows that the three companies' stock price histogram is not normally distributed due to the kurtosis and skewness values. The histogram also shows that all three companies have more than one peak with different mean or location and variance. Moreover, it indicates a non-stationary process on mean and variance, which represents a mixture of distribution. This is in accordance with the results of the Dicky Fuller test in the three serial data, which does not reject the null hypothesis. Therefore, the mixture nature, of these three stock price movements tends to fluctuate around every mode of mixture component at their peak of multi-modality patterns. Prices also move from one component to another with a survival probability of the previous regime. In order to have the stationary process on mean, it is necessary to stabilize the data by differencing it on lag 1. Dicky Fuller's test rejected the null hypothesis and stated that the differencing data is stationary on the mean.

Figure 3 shows the histogram data after being stationary on the mean and the characteristic of the leptokurtic and fat tail. It is difficult to represent this pattern using the uni-modal normal distribution. Therefore, the differencing processes are unable to eliminate the variance differences in the data. This result is further analyzed by using the Mathematica software supports to test the mean difference of the Wolfram Mathworld's person chi-square [18]. Therefore, the differencing data still has a multi-modal pattern, which indicates a structural changed model [19]. 


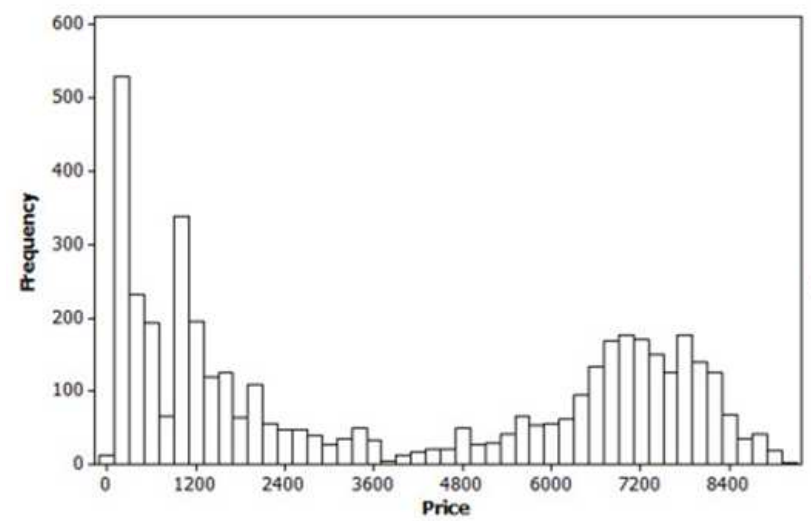

(a)

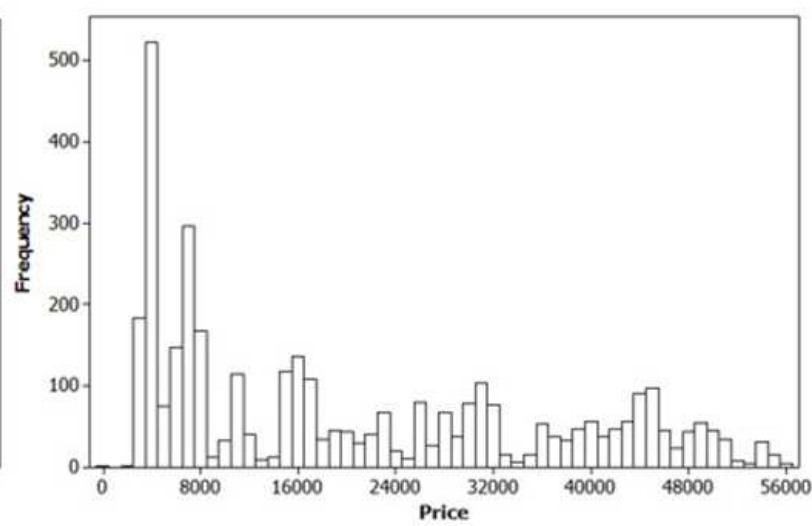

(b)

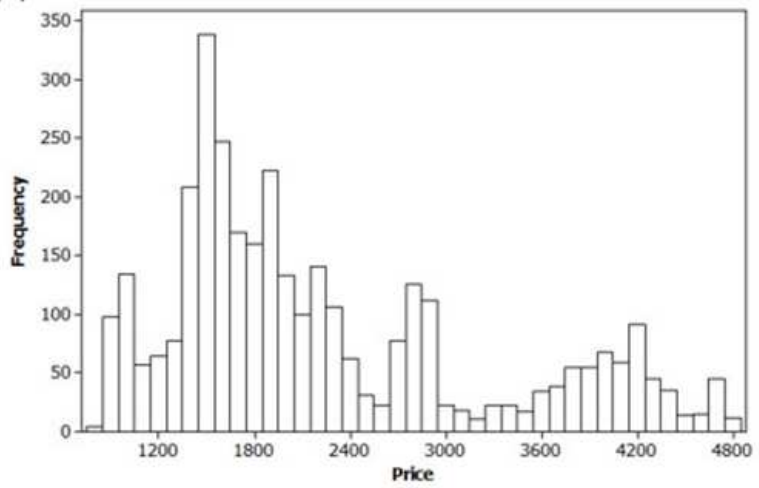

(c)

Figure 2: Histogram of Shares (a) PT. Astra International, (b) PT. Unilever Indonesia and (c) PT. Telekomunikasi Indonesia, before Differencing

\subsection{Markov Switching Model}

From the multi-modality testing results, three serial data are modeled using MSwM provided by $\mathrm{R}$ software. This helps to detect the possibility of having a significant change in the model structure. Based on the best overfitting model of autoregressive on the fixed number of switching regimes, the two serial data shares, i.e. PT. Unilever and PT. Telekomunikasi are modeled with $\mathrm{MSw}(2)-\mathrm{AR}(2)$. While the stock price data of PT. Astra International is modeled into three regimes, namely $\mathrm{MSw}(3)-\mathrm{AR}(2)$. When the MSwM with three regimes is implemented on the previous two serial data, the EM process becomes unstable and unable to meet the convergence [20]. The modeling results obtained are shown in Tables 5, 7, and 9. Meanwhile, the AIC value as a benchmarking tool for the model selection is shown in Table 4 with the successive analysis presented in Figure 3.

\subsubsection{The MSwM-AR for Stock Price of PT. Astra International}

The serial data of PT Astra International's stock price is modeled into two and three regimes. The model with three regimes has smaller AIC with the probability of the AR (2) sequentially surviving with values of 0.988105, 0.962038, and 0.942029, respectively, as shown in Table 6 . In addition, Table 5 shows the three different typical regime behaviors, which elaborates on the pattern of the data. All three regimes are simultaneously affected by the two previous lag data. Conversely, the first and third regimes are positively influenced by a previous lag, while the 


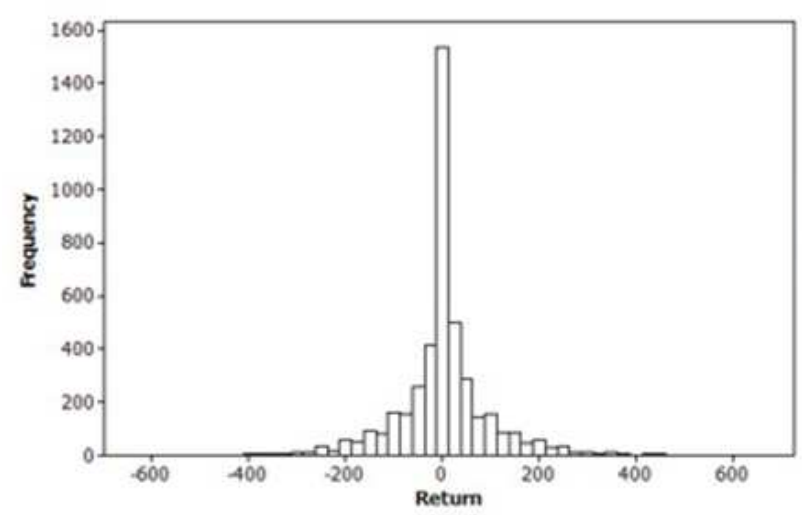

(a)

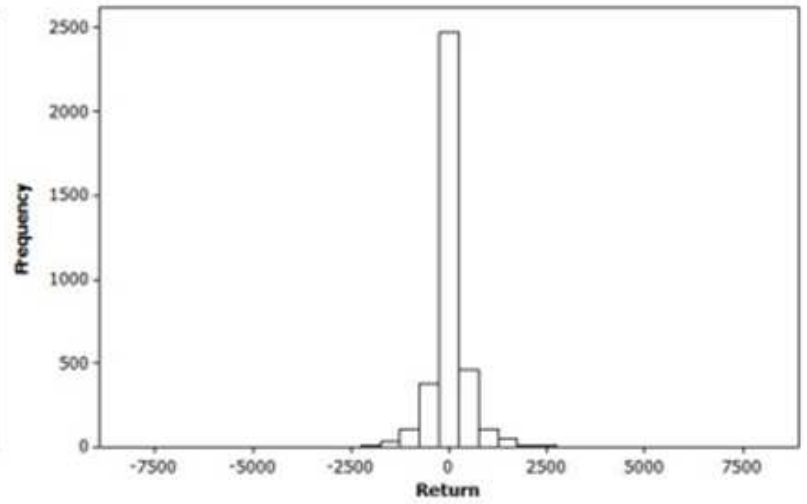

(b)

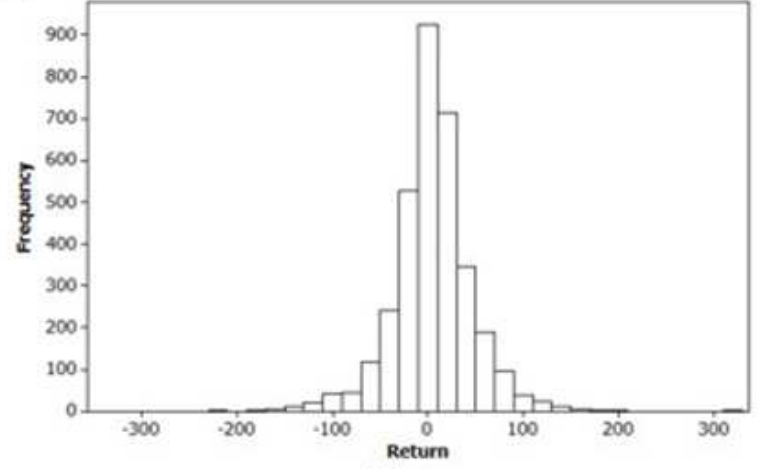

(c)

Figure 3: Histogram of Shares: (a) PT. Astra International, (b) PT. Unilever Indonesia and (c) PT. Telekomunikasi Indonesia, after Differencing

second regime, and give a negative effect. The difference in their intercepts shows that their modes tend to be different, although relatively small, to explain multi-modalities coupled with striking standardized residual.

The shadowed plot in Figure 4 shows the dominance of each regime over time of transactions on these shares. It shows that regime 1 occurs in the initial period of the IPO and represents a data pattern concentrating around zero to form a leptokurtic distribution in Figure 3 (a). Meanwhile, Regime 2 dominates at the end of the transaction period until 2018. Regime 3 occurs in the middle of the period during data collection from the IPO in 2000 to 2018. Based on the standard residual values in Table 4, Regime 2 is the most fluctuating model for capturing the left and right fat-tails data patterns shown in Figure 3(a).

Table 4: Values for the Three Companies

\begin{tabular}{|c|c|c|c|}
\hline Model & $\begin{array}{l}\text { PT. Astra } \\
\text { International }\end{array}$ & $\begin{array}{l}\text { PT. Unilever } \\
\text { Indonesia }\end{array}$ & $\begin{array}{l}\text { PT. Telekomunikasi } \\
\text { Indonesia }\end{array}$ \\
\hline $\mathrm{MSw}(2)-\mathrm{AR}(2)$ & $48,353.5$ & $52,305.8$ & $48,308.7$ \\
\hline $\mathrm{MSw}(3)-\mathrm{AR}(2)$ & $47,439.8$ & - & - \\
\hline
\end{tabular}


Table 5: Markov Switching Model of PT. Astra International

\begin{tabular}{|c|c|c|c|c|c|}
\hline \multirow{5}{*}{ Regime 1} & & Estimate & Std. Error & $\mathrm{t}$ value & $\operatorname{Pr}(>|t|)$ \\
\hline & Intercept & 1.4647 & 1.0344 & 1.4160 & 0.1568 \\
\hline & $\Phi_{1}$ & 0.0515 & 0.0356 & 1.4466 & 0.1480 \\
\hline & $\Phi_{2}$ & -0.0234 & 0.0313 & -0.7476 & 0.4547 \\
\hline & $\begin{array}{l}\text { Median (Standardized } \\
\text { Residual) }\end{array}$ & $-5.60 \mathrm{E}-04$ & & & \\
\hline \multirow{5}{*}{ Regime 2} & & Estimate & Std. Error & $\mathrm{t}$ value & $\operatorname{Pr}(>|t|)$ \\
\hline & Intercept & 2.3824 & 2.8808 & 0.8270 & 0.408237 \\
\hline & $\Phi_{1}$ & -0.0064 & 0.0005 & -12.8000 & $2.20 \mathrm{E}-16$ \\
\hline & $\Phi_{2}$ & -0.0584 & 0.0209 & -2.7943 & 0.005201 \\
\hline & $\begin{array}{l}\text { Median (Standardized } \\
\text { Residual) }\end{array}$ & -0.0013089 & & & \\
\hline \multirow{5}{*}{ Regime 3} & & Estimate & Std. Error & $\mathrm{t}$ value & $\operatorname{Pr}(>|t|)$ \\
\hline & Intercept & 0.3373 & 0.2495 & 1.3519 & 0.176407 \\
\hline & $\Phi_{1}$ & 0.0841 & 0.0282 & 2.9823 & 0.002861 \\
\hline & $\Phi_{2}$ & -0.0019 & 0.0031 & -0.6129 & 0.539942 \\
\hline & $\begin{array}{l}\text { Median (Standardized } \\
\text { Residual) }\end{array}$ & 0 & & & \\
\hline
\end{tabular}

Changes in the price of PT Astra International shares during the study ended with Regime 2, as shown in Figure 4 (b). Investment in this stock is more appropriate, with a probability of 0.988105 based in Regime 2, and as shown in Table 6 .

\subsubsection{The MSwM-AR for Stock Price of PT. Unilever Indonesia}

The PT Unilever stock price's serial data is modeled into two regimes containing AR (2) with the transition probability, as shown in Table 8. Once the price enters Regime 1 and 2, it remains there with the probability of 0.934086 and 0.941786 , respectively. Price fluctuations from the time of the IPO until 2018 is shown in Figure 5(a) with frequent occurrence in Regime 1. Furthermore, the dominance of transaction time is also visualized by the shadowed plot in Figure 5(a). This is more volatile than Regime 2, as shown in the standard residue in Table 7. The two regimes were influenced by the previous lag data, which had a negative effect with a multi-modal pattern comprising of different standardized residuals. The data pattern of Figure 3(b) is explained by the combination of Regime 2, which explains its leptokurtic pattern with smaller standardized residuals as well as Regime 1 analyzes the fat-tail pattern with a platykurtic distribution. 
Table 6: Transition Probability for the Switching Regimes for PT. Astra International

\begin{tabular}{|l|l|l|l|}
\hline & Regime 1 & Regime 2 & Regime 3 \\
\hline Regime 1 & 0.942029 & 0.011175 & 0.036857 \\
\hline Regime 2 & 0.024094 & 0.988105 & 0.001105 \\
\hline Regime 3 & 0.033877 & 0.00072 & 0.962038 \\
\hline
\end{tabular}

Table 7: Markov Switching Model of PT. Unilever Indonesia

\begin{tabular}{|l|l|r|r|r|r|}
\hline & & Estimate & Std. Error & $\mathrm{t}$ value & $\operatorname{Pr}(>|\mathrm{t}|)$ \\
\cline { 2 - 6 } Regime 1 & Intercept & 27.6880 & 19.199 & 1.4422 & 0.149246 \\
\cline { 2 - 6 } & $\Phi_{1}$ & -0.2950 & 0.0262 & -11.2595 & $2.20 \mathrm{E}-16$ \\
\cline { 2 - 6 } & $\Phi_{2}$ & -0.1042 & 0.0273 & -3.8168 & 0.000135 \\
\hline \multirow{5}{*}{ Regime 2 } & $\begin{array}{l}\text { Median (Standardized } \\
\text { Residual) }\end{array}$ & -0.9148836 & & & \\
\cline { 2 - 6 } & Intercept & Estimate & Std. Error & t value & $\operatorname{Pr}(>|\mathrm{t}|)$ \\
\cline { 2 - 6 } & $\Phi_{1}$ & 3.5280 & 2.6529 & 1.3299 & 0.1836 \\
\cline { 2 - 6 } & $\Phi_{2}$ & -0.0147 & 0.0135 & -1.0889 & 0.2762 \\
\cline { 2 - 6 } & $\begin{array}{l}\text { Median (Standardized } \\
\text { Residual) }\end{array}$ & $-7.44 \mathrm{E}-0.0116$ & 0.0103 & -1.1262 & 0.2601 \\
\hline
\end{tabular}

Regime 1 dominates the changes and records the share price of PT. Unilever at the end of the period, as shown in Figure 5(a). Therefore, investors in these shares make their investment decisions the next day while still using this Regime 1 with a probability of 0.934086 , as shown in Table 8.

\subsubsection{The MSwM-AR for Stock Price of PT. Telekomunikasi Indonesia}

This sector consists of two regimes of AR (2), namely MSw(2)-AR(2), as shown in Figure 6. Their domination is separated in two different models, from the beginning of the IPO for Regime 2 and at the end of 2018 for Regime 1, which is visualized by the overshadowed plot in Figure 10. The first regime is significantly more fluctuating than the second, as shown in Figure 6, with a greater standardized residual in Table 9 . Regime 1 is in charge of analyzing the fat tail data pattern, while Regime 2 explains the leptokurtic as a representation of Figure 3(c). Table 9 also shows the typical regime behaviors, which elaborates on the pattern. Both one and two previous lag data together had a negative effect on the changes in the patterns of the two regimes with a relatively large different intercept representing the significant structural change model with different standardized residuals. 


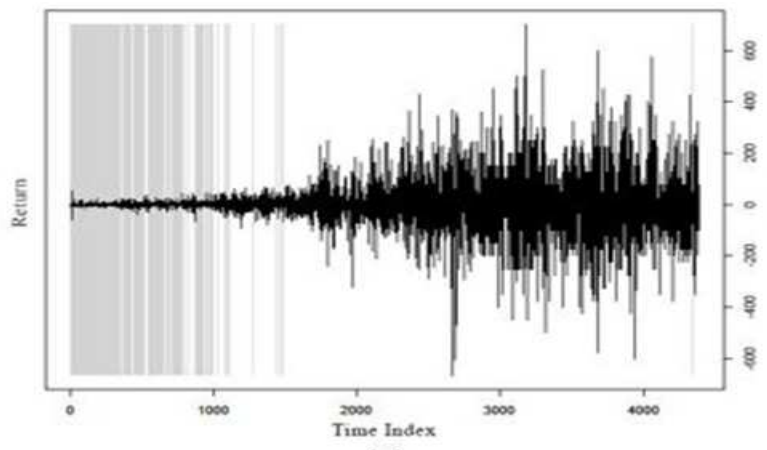

(a)

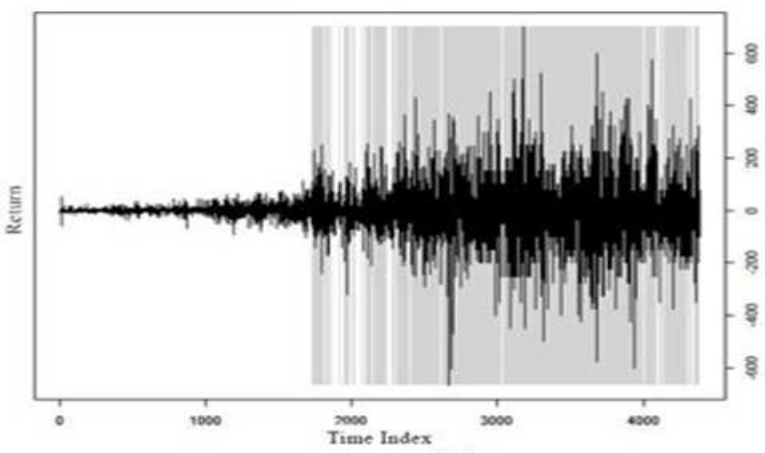

(b)

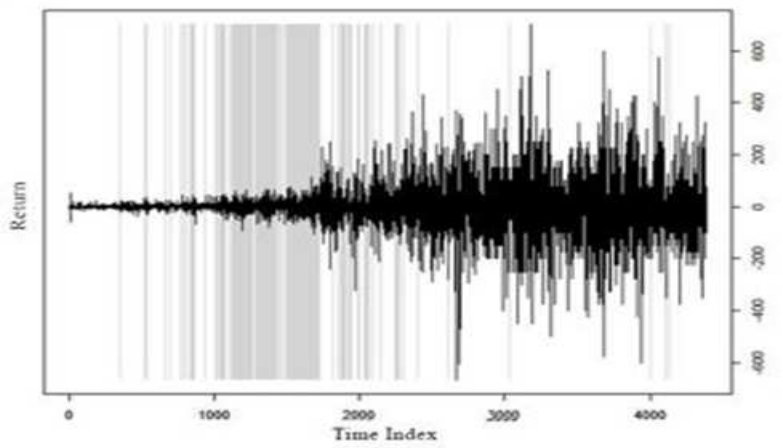

(c)

Figure 4: Plot of the three Dominated Regimes of Price Model of PT. Astra International during the Trading. (a) Regime 1, (b) Regime 2, and (c) Regime 3

Table 8: Transition Probability for the Switching Regimes for PT. Unilever Indonesia

\begin{tabular}{|l|l|l|}
\hline & Regime 1 & Regime 2 \\
\hline Regime 1 & 0.934086 & 0.058214 \\
\hline Regime 2 & 0.065914 & 0.941786 \\
\hline
\end{tabular}

Figure 6(a) shows the dominance of Regime 1 at the end of the PT. Telekomunikasi stock data period. Meanwhile, Table 10 shows the transition matrix, with a probability of 0.938343 , which means that investors tend to make their investment decisions by continuing to use Regime 1 the next day.

\section{Conclusion and Future Research}

The MSwM(.)-AR (.) method has demonstrated its capability to detect the possibility of a structural change in the model and the serial data. The PT. Astra International, PT. Unilever, and PT. Telekomunikasi shares helped provide proof of success and validated the workings of this modeling approach. This article, therefore, suggests the use of Regime 1 to invest in the shares of PT. Telekomunikasi and PT. Unilever, with Regime 2 in PT. Astra International shares. 


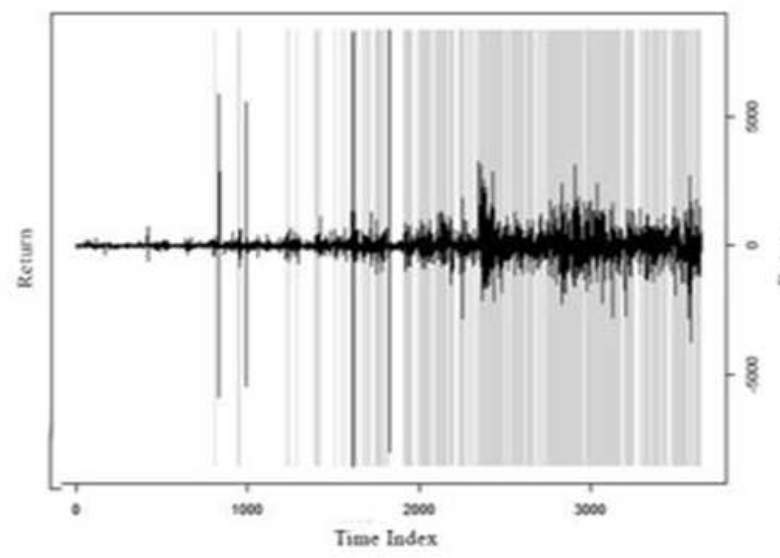

(a)

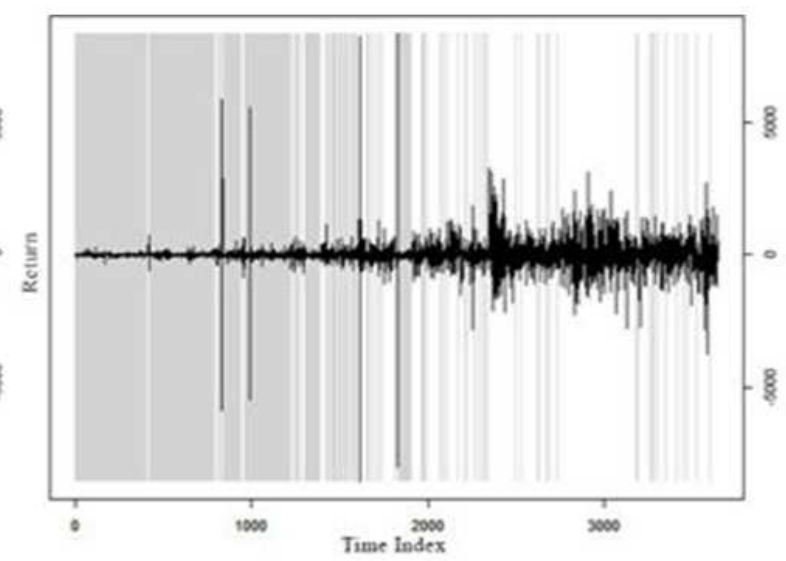

(b)

Figure 5: Plot of the Two Dominated Regimes of Price Model of PT. Unilever Indonesia during the Trading. (a) Regime 1 and (b) Regime 2

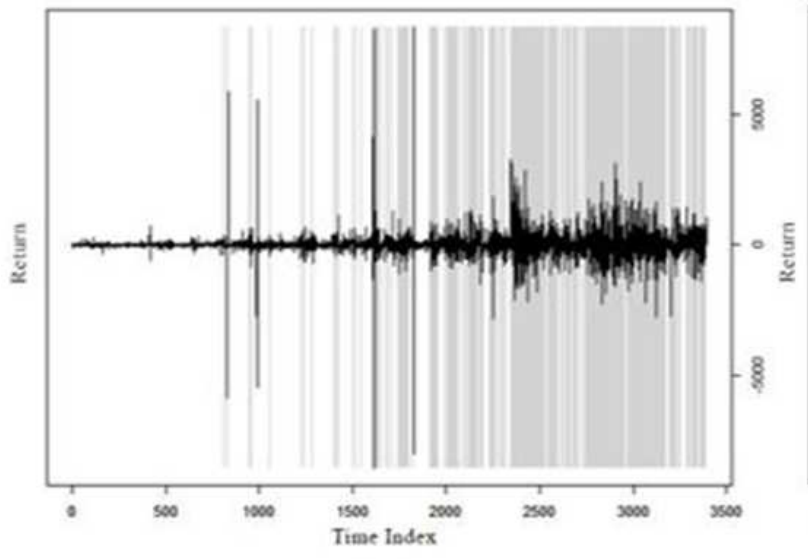

(a)

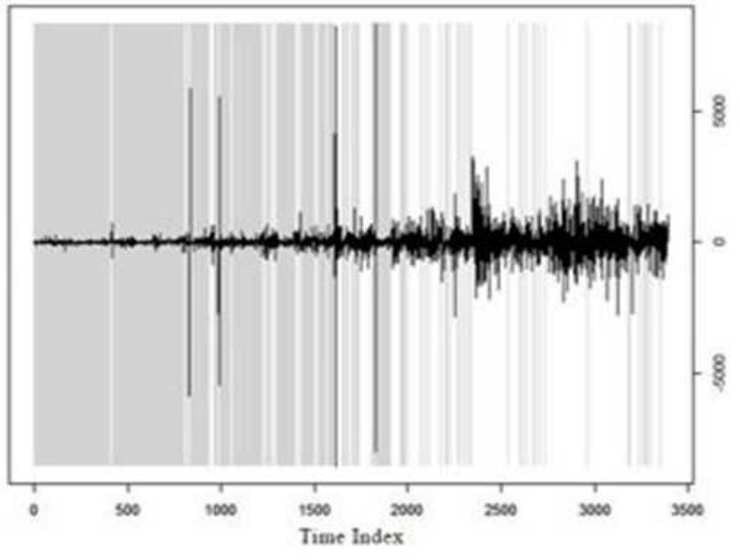

(b)

Figure 6: Plot of the Two Dominated Regimes of Price Model of PT. Telekomunikasi Indonesia during the Trading. (a) Regime 1 and (b) Regime 2

In this study, it is still assumed that the number of regimes is fixed throughout the data series. Therefore, further studies need to be conducted to determine the number of regions that comply with MSwM (.) - AR (.) adaptively. This is needed by the investor to determine the best model when there is a sudden change in the number of regimes which is used to estimate the value of stock prices in the next few steps. This is because the serial data patterns have a number of broken structures that are not always fixed over time, and the series of stock prices are also alternately changing between one model and another. The latest $j$-th regime model tends to represent the price of stock trading with the probability represented in the transition matrix of the Markov Chain of $P_{j j}$. 
Table 9: Markov Switching Model of PT. Telekomunikasi Indonesia

\begin{tabular}{|l|l|r|r|r|r|}
\hline & & Estimate & Std. Error & $\mathrm{t}$ value & $\operatorname{Pr}(>|\mathrm{t}|)$ \\
\cline { 2 - 6 } & Intercept & 37.1934 & 21.0333 & 1.7683 & 0.077011 \\
\cline { 2 - 6 } Regime 1 & $\Phi_{1}$ & -0.3244 & 0.0293 & -11.0717 & $2.20 \mathrm{E}-16$ \\
\cline { 2 - 6 } & $\Phi_{2}$ & -0.0999 & 0.0309 & -3.2330 & 0.001225 \\
\cline { 2 - 6 } & $\begin{array}{l}\text { Median (Standardized } \\
\text { Residual) }\end{array}$ & -1.082066 & & & \\
\hline \multirow{5}{*}{ Regime 2 } & & Estimate & Std. Error & $\mathrm{t}$ value & $\operatorname{Pr}(>|\mathrm{t}|)$ \\
\cline { 2 - 7 } & Intercept & 3.9206 & 2.8243 & 1.3882 & 0.1651 \\
\cline { 2 - 7 } & $\Phi_{1}$ & -0.0212 & 0.0155 & -1.3677 & 0.1714 \\
\cline { 2 - 6 } & $\Phi_{2}$ & -0.0175 & 0.0126 & -1.3889 & 0.1649 \\
\cline { 2 - 6 } & Median (Standardized & $-8.33 \mathrm{E}-04$ & & & \\
& Residual) & & & & \\
\hline
\end{tabular}

Table 10: Transition Probability for the Switching Regimes for PT. Telekomunikasi Indonesia

\begin{tabular}{|l|l|l|}
\hline & Regime 1 & Regime 2 \\
\hline Regime 1 & 0.938343 & 0.048754 \\
\hline Regime 2 & 0.061657 & 0.951246 \\
\hline
\end{tabular}

\section{References}

[1] Kompas. Retrieved from Kompas.com: https://ekonomi.kompas.com/read/2018/ 06/21/060200726/ihsg-merosot-saatnya-incar-saham-blue-chip, June 21, 2018.

[2] Satchell, S. Regime switching in financial markets. Journal of Asset Management. 2011. 12: 309 .

[3] Huarng, K. H. An occurrence based regime switching model to improve forecasting. Management Decision. 2014. 52(7): 1255-1262.

[4] Hamilton, J. D. A new approach to the economic analysis on non-stationary time series and the business cycles. Econometrica. 1989. 57(2): 357-384.

[5] Hamilton, J. D. Analysis of time series subject to changes in regime. Journal of Econometrics. 1990. 45: 39-70.

[6] Syllignakis, M. N. and Kouretas, G. P. Markov-switching regimes and the monetary model of exchange rate determination: Evidence from the Central and Eastern European markets. Journal of International Financial Markets, Institutions \&3 Money. 2011. 21: 707- 723. 
[7] Fuentes, C. A. and Rios, R. Non-explicit FOREX intervention: The role of the central reserve bank in a dollarized economy and its effects on expectations from the "peso problem" perspective: The case of Peru. Journal of Business Research. 2014. 67(4): 558566.

[8] Huarng, K.-H., Yu, T.H.-K., and Kao, T. T. Analyzing structural changes using clustering techniques. International Journal of Innovative Computing Information and Control. 2008. 4(5): 1195-1201.

[9] Huarng, K. H., Yu, T. H. K. and Parellada, F. S. An innovative regime switching model to forecast Taiwan tourism demand. The Service Industries Journal. 2011. 31(10): 1603-1612.

[10] Huarng, K. Identifying regime switches using causal recipes. Journal of Business Research. 2016. 69, 1498-1502, DOI: 10.1016/j.jbusres.2015.10.131

[11] Persio, L. D. and Frigo, M. Gibbs sampling approach to regime switching analysis of financial time series. Journal of Computational and Applied Mathematics. 2016. 300: 4355. DOI: 10.1016/j.cam.2015.12.010.

[12] Hamilton, J. D. Specification Testing in Markov-switching Time Series Models. Journal of Econometrics. 1996. 70: 127-157.

[13] Kim, C. J and Nelson C. R. State Space Models with Regime Switching, Classical and Gibbs Sampling Approaches with Applications. Cambridge, MA: MIT Press. 1999

[14] Persio, L.D. and Frigo, M. Maximum likelihood approach to Markov switching models. WSEAS Transactions on Business and Economics. 2015. 12: 239-242.

[15] Dempster, A. P., Laird, N. M. and Rubin, D. B., Maximum likelihood from incomplete data via the EM algorithm (with discussion). Journal of the Royal Statistical Society Series B. 1977. 39: 1-38. DOI: 10.1.1.133.4884.

[16] Frühwirth-Schnatter, S. Finite Mixture and Markov Switching Models. Springer: New York. 2006.

[17] Chuffart, T. Selection Criteria in Regime Switching Conditional Volatility Models. Econometrics. 2015(3): 289-316. DOI:10.3390/econometrics3020289.

[18] Weisstein, E.W. Normal Distribution. From MathWorld-A Wolfram Web Resource. http://mathworld.wolfram.com/NormalDistribution.html, downloaded on March 20, 2019.

[19] Berk, K., Hoffmann, A. and Müller, A. Probabilistic Forecasting of Industrial Electricity Load with Regime Switching Behavior. International Journal of Forecasting. 2018. 34: 147-162. DOI: 10.1016/j.ijforecast.2017.09.006.

[20] Susanto, I., Iriawan, N., Kuswanto, H., Suhartono, Fithriasari, K., Ulama, B.S.S., Suryaningtyas, W. and Pravitasari, A. A. On the Markov Chain Monte Carlo Convergence Diagnostic of Bayesian Finite Mixture Model for Income Distribution. Journal of Physics: Conference Series. 2018. 1090(1), 012014, DOI: 10.1088/1742-6596/1090/1/012014. 